\title{
Retraction Note to: Overexpression of a cotton annexin gene, GhAnn 1, enhances drought and salt stress tolerance in transgenic cotton
}

\author{
Feng Zhang ${ }^{1}$. Shufen $\mathrm{Li}^{1}$ · Shuming Yang ${ }^{1}$ - Like Wang ${ }^{1}$. Wangzhen Guo ${ }^{1}$
}

Published online: 4 September 2018

(c) Springer Nature B.V. 2018

\section{Retraction to: Plant Molecular Biology (2015) 87:47-67 https://doi.org/10.1007/s11103-014-0260-3}

The authors are retracting this article (Zhang et al. 2015) because irregularities were involved in the reuse of stomatal images in Fig. 9. In details, (1) stomatal image in 0d:S-1 (A) is the same as that in 3As-1 (A); (2) 0d:As-1 (A) was reused in mock As-1 and in mock 3As-1(D); (3) 20d:S-1 (A) and 20d:S-2 (A) were reused in ABA:As-1(D) and ABA:As-2 (D), respectively.

The authors regret any inconvenience or trouble caused by the original publication and apologize sincerely to the readers, reviewers, and editors of Plant Molecular Biology. All authors agree to this retraction.

\section{Reference}

Zhang F, Li S, Yang S, Wang L, Guo W (2015) Overexpression of a cotton annexin gene, GhAnn1, enhances drought and salt stress tolerance in transgenic cotton. Plant Mol Biol 87:47-67. https:// doi.org/10.1007/s11103-014-0260-3

Wangzhen Guo

moelab@njau.edu.cn

1 State Key Laboratory of Crop Genetics and Germplasm

Enhancement, Hybrid Cotton R \& D Engineering

Research Center, MOE, Nanjing Agricultural

University, Nanjing 210095, Jiangsu Province,

People's Republic of China 